\title{
O módulo São José do Rio Preto do Projeto Geo-Escola - uma experiência educacional diferenciada
}

\author{
Joseli Maria Piranha' \& Celso Dal Ré Carneiro ${ }^{2}$
}

\begin{abstract}
Resumo No município de São José do Rio Preto, situado na região noroeste do Estado de São Paulo, o desenvolvimento do Projeto Geo-Escola constituiu pesquisa em ensino-aprendizagem de Geologia, segundo o modelo de investigação de estudo de caso. A experiência possibilitou que os participantes - professores de Ciências e Geografia - se apropriassem de saberes das Geociências importantes para construção de conhecimentos profissionais e para construção de cidadania. Vários recursos didáticos foram utilizados, com destaque para trabalhos de campo, que sensibilizaram os participantes e despertaram certa identidade com o meio que os cerca, na medida em que ofereceram vivência singular. O processo expôs conceitos revelados na teoria, mas, sobretudo, levou-os a identificar, visualizar e compreender mais profundamente o ensino e a legitimá-lo. Se a investigação estruturou-se pela tese de que o conhecimento das Geociências exerce papel especial na educação para sustentabilidade da vida, os resultados obtidos permitiram confirmar que, na relação dinâmica do ensinoaprendizagem, o conhecimento de Geologia é essencial para o cidadão desenvolver uma cultura da Terra. Assim, a pesquisa não somente revela potenciais, evidencia compromissos e sugere rotas, mas também aponta para o tratamento de problemas ambientais mais amplos, que envolvem a sustentabilidade.
\end{abstract}

Palavras-chaves: Ensino de Geociências, Ensino de Ciências, Ensino profissional, Educação científica, Estudo de caso.

\begin{abstract}
The module São José do Rio Preto of Geo-Escola Project - a differentiated educational experience. The development of Geo-Escola Project in the municipality of Sao Jose do Rio Preto, situated in the northeast part of the Sao Paulo State, is an educational experience on Geology. It is a study of case. The activities allowed the participants - teachers of Science and Geography- to adopt Geosciences as the basis of getting a professional knowledge which, as citizens, they need as well. Geology is essentially a historical science of Nature, an inheritance of human knowledge that aims at the understanding of the materials, processes and products of planetary evolution in all senses. Several kinds of educational resources were used, especially fieldwork, allowing the participants to create an identity with the world around them, a result of singular importance. The research has exposed concepts revealed in theory as long as it also allowed one to identify and to visualize the related concepts and to get a deeper understanding of teaching. It has also legitimated the overall process: if the investigation adopts the premise that Geoscience knowledge plays a special role in an education for sustainability of life as a starting point, the obtained results allow to confirm it.
\end{abstract}

Keywords: Geoscience Education, Science Education, Professional Education, Scientific Literacy, Case study.

INTRODUÇÃO A preocupação com o ensino das Geociências na educação básica brasileira tem promovido estudos para avaliação do potencial papel que as Ciências da Terra têm a desempenhar na formação da sociedade atual e dos futuros cidadãos.

Nesse contexto o Projeto Geo-Escola (Carneiro \& Barbosa 2005: 73) surgiu em 2002, tendo como pressupostos que: (a) inexiste na educação básica brasileira uma disciplina específica que abrigue os conteúdos das Geociências; (b) os conhecimentos das Geociências limitam-se a inserções esparsas nas disciplinas de Geografia e Ciências; (c) ocorre predomínio de aulas expositivas, eventualmente ilustradas pelo professor e (d) não se reconhece o grau de utilização, nem tampouco a validade do uso do computador como ferramenta didática para o ensino das Geociências.

A criação do projeto se deu a partir de duas hipóteses básicas de trabalho: (1) as informações sobre a Geologia de uma determinada região são do interesse direto dos docentes que nela exercem seu trabalho; (2) são poucos os casos no Brasil de aproveitamento de conhecimentos de geologia regional para produção de materiais didáticos em Geociências, para uso na educação básica local.

Assim, o Projeto Geo-Escola (http:/www.geoescola.pro.br) foi desenvolvido para: disponibilizar da-

1 - UNESP, Instituto de Biociências, Letras e Ciências Exatas, Depto. Química e Ciências Ambientais, São José do Rio Preto (SP), Brasil.E-mail: joseli@ibilce.unesp.br

2 - Universidade Estadual de Campinas, Instituto de Geociências, Depto. Geociências Aplicadas ao Ensino, Campinas (SP), Brasil. E-mail: cedrec@ige unicamp.br 
dos geológicos, imagens e mapas, de uma dada região, em formato de material didático com suporte em computador, a professores de ensino fundamental e médio (Carneiro \& Barbosa 2005: 71).

O módulo-piloto, desenvolvido na região paulista de Jundiaí-Atibaia, evidenciou o interesse na aplicação dessa linha de investigação em outras regiões do Estado e do país. A realização de novos módulos, em diferentes regiões ou municípios, permitiria levar adiante o objetivo central do Projeto, bem como aprofundar as investigações em tópicos que o primeiro módulo revelou importantes e outros, ainda, relativos ao ensino de Geociências na Educação Básica brasileira.

A iniciativa teve curso com o desenvolvimento do segundo módulo do Projeto Geo-Escola, no município de São José do Rio Preto, e deu origem à tese de doutoramento da primeira autora (Piranha 2006). Este artigo tem a finalidade de expor e analisar as características do material do material produzido para sustentar a pesquisa, o perfil do grupo de professores que se envolveu ativamente nas atividades, e os principais indicadores adotados na análise crítica dos resultados obtidos.

Objeto de estudo: o módulo São José do Rio Preto do Projeto Geo-Escola O módulo São José do Rio Preto tratou da problemática do ensino-aprendizagem das Geociências. No módulo buscou-se investigar quais saberes das Geociências, e em que medida, são importantes para a construção de uma cultura inovadora, comprometida com a sustentabilidade. Somou-se aos objetivos básicos do Projeto Geo-Escola a proposta de fomentar o uso da informação geológica local e trabalhos de campo,como instrumentos didáticos.

O Módulo São José do Rio Preto do Projeto Geo-Escola foi desenvolvido por meio de: (a) organização sistemática da informação geológica local na elaboração de material didático com suporte no computador, (b) oferta do material didático concomitante com a (c) oferta de cursos teóricos e práticos ao público-alvo e (d) desenvolvimento de instrumentos de avaliação, que permitissem dimensionar os efeitos dos procedimentos adotados.

Dois fatores foram determinantes para o sucesso da iniciativa, a saber: a existência de um Diagnóstico Geo-Ambiental do município (Piranha et al. 2004) com amplo acervo de informações geológicas e relativas à ocupação e desenvolvimento local, e o reconhecimento, empenho e demonstração de interesse de várias pessoas, com as quais se pôde trabalhar.

Assim, buscou-se avaliar o grau de interesse de pessoas sabidamente sensíveis tanto para as causas e objetivos da educação, quanto atentos às questões ambientais: todos eles são professores de educação básica. Diante da plena aceitação dos educadores ao convite para integrarem um grupo de estudo em ensino de Geociências e, sobretudo, pelos interesses específicos que eles revelaram ter relativamente ao seu conteúdo - poluição e contaminação ambiental, uso racional da água, água no ambiente e roteiros de campo para educação ambiental - pode-se reconhecer a importância da proposta, e assim empenhar esforços para o seu desenvolvimento.

A investigação foi realizada com professores de Ciências e Geografia, das escolas de ensino fundamental e médio das redes municipal, estadual e particular de ensino formal do município de São José do Rio Preto. $\mathrm{Na}$ definição do público-alvo foi essencial o propósito de trabalhar o ensino das Geociências, com potenciais multiplicadores das informações e saberes geológicos. Dessa forma, poder-se-ia aquilatar o alcance dos trabalhos educacionais na formação de uma cultura diferenciada e seu alcance para mudanças de comportamento individual e comunitário das pessoas envolvidas e de outras, que elas pudessem alcançar.

Assim, o módulo São José do Rio Preto do Projeto Geo-Escola buscou avaliar o significado do ensino das Geociências na relação dinâmica do trinômio prática docente - conhecimento construído - ampliação cultural docente, para assim, poder avaliar suas implicações na capacitação pessoal e coletiva, por uma educação formadora de uma cultura de sustentabilidade da vida (Piranha \& Carneiro 2009).

Método de investigação $\mathrm{Na}$ experiência didática desenvolvida buscou-se enfatizar a perspectiva holística dada pelo estudo do Sistema Terra, o uso da informação geológica local - por entendê-la capaz de revelar um contexto cotidiano relevante aos aprendizes (Orion 2001: 99) -, o emprego de recursos didáticos informatizados e a oferta de cursos com trabalhos de campo, como ferramentas didáticas para o ensino.

$\mathrm{O}$ método de investigação assumido centrou-se no levantamento, reunião e interpretação de informações diversas que constituem a fundamentação lógica, a dimensão histórica e a contextualização teórica da problemática estudada, aspectos característicos da modalidade investigativa identificada como Estudo de Caso (Lüdke \& André 2003).

\section{A disponibilidade de dados e informações geológicas} locais para preparo de materiais didáticos $\mathrm{O}$ município de São José do Rio Preto, instalado em substrato geológico constituído por rochas do Grupo Bauru (Bacia do Paraná), registrou, a partir do final da década de 1970, um crescimento urbano acelerado e descontrolado. Esse crescimento tornou crítica a situação de uso dos recursos naturais do meio físico, e mais especialmente dos recursos hídricos. A situação local passou a evidenciar a necessidade de urgentes medidas de gestão, para recuperar áreas degradas e melhorar a qualidade de vida.

Nesse sentido, os autores J. M. Piranha (Brighetti) \& A. Pacheco iniciaram, na década de 1990, uma série de trabalhos de levantamento e caracterização de fontes potenciais de poluição de recursos hídricos no município (Brighetti 1992, Brighetti et al. 1995). Paralelamente, foram desenvolvidos estudos do abastecimento público local e das características de uso e explotação das principais reservas hídricas superficiais e subterrâneas, que constituem fontes de suprimento de águas no município (Santos et al. 2001, Piranha et al. 2004). 
Tais estudos permitiram a elaboração de mapas temáticos de ocupação do meio físico, no que se refere à demanda hídrica e à situação ambiental do município. Possibilitaram ainda a confecção de bancos de dados que constituem subsídio ao planejamento do desenvolvimento urbano e rural, com especial atenção ao uso das reservas hídricas, seu aproveitamento, comprometimento, riscos, controle e mitigação de impactos e recuperação.

As informações geológicas, conhecidas a partir desses estudos, possibilitaram a elaboração do Diagnóstico Geo-Ambiental do município de São José do Rio Preto (Piranha et al. 2004). Este trabalho, além de constituir instrumento para elaboração de políticas de gestão de recursos naturais, também tem proporcionado a elaboração de materiais didáticos para ensino de Geociências, tanto nos níveis de educação formal, quanto nos meios de educação não-formal (cursos de formação continuada, cursos de extensão, cursos e programas de difusão cultural).

Nesse sentido, os dados geológicos obtidos nesses trabalhos puderam ser incorporados na pesquisa, vindo a integrar o material didático em formato CD-ROM, elaborado para o desenvolvimento do módulo São José do Rio Preto do Projeto Geo-Escola (Carneiro et al. 2004).

Para a composição do material didático em formato digital - CD-ROM educativo (Carneiro op. cit. 2004; Fig. 1) - foram utilizados recursos de linguagem computacional amplamente difundida, adotando-se programas comuns no mercado. Foi utilizado o Editor Geo-Escola - ferramenta de software livre - que fora desenvolvido no primeiro módulo do projeto, atendendo à preocupação que cerca a questão de custos de licenças dos softwares comerciais (Carneiro \& Barbosa 2003).

O conteúdo do CD-ROM, todo voltado aos conhecimentos de Geociências, buscou elucidar e tratar das esferas terrestres, dos materiais e processos geológicos, da ocupação antrópica dos recursos naturais e do diagnóstico geo-ambiental de São José do Rio Preto.

$\mathrm{O}$ destaque do conteúdo recai sobre o fato de que se pôde disponibilizar os resultados de pesquisas anteriores da autora, para uso no módulo Geo-Escola São José do Rio Preto. Isso possibilitou o atendimento da demanda de conhecimentos estabelecida e priorizada pelos professores participantes. Os materiais didáticos foram elaborados em função de necessidades e carências declaradas pelos professores, interessados em participar da investigação.

Relativamente à organização do conteúdo no CD-ROM educativo, merecem destaque: (a) a pasta EDITOR, que comporta arquivos de instalação do Editor Geo-Escola (Barbosa 2003) e sequências, criadas com este, para demonstrar as opções e recursos dessa ferramenta de uso livre (freeware); (b) a pasta FOTOS: contendo 376 arquivos de fotos, de autoria própria da pesquisadora, obtidas durante os trabalhos de campo que realizou no município de São José do Rio Preto, no período de 1992 a meados de 2004. Aos arquivos de imagens de cada pasta, foi agregado um arquivo em Word, contendo a descrição das respectivas imagens e ainda a localização exata destas no município de São José do Rio Preto; (c) a pasta MAPAS: contendo nove apresentações, que exibem mapas previamente elaborados em ambiente CAD, resultantes de pesquisas prévias
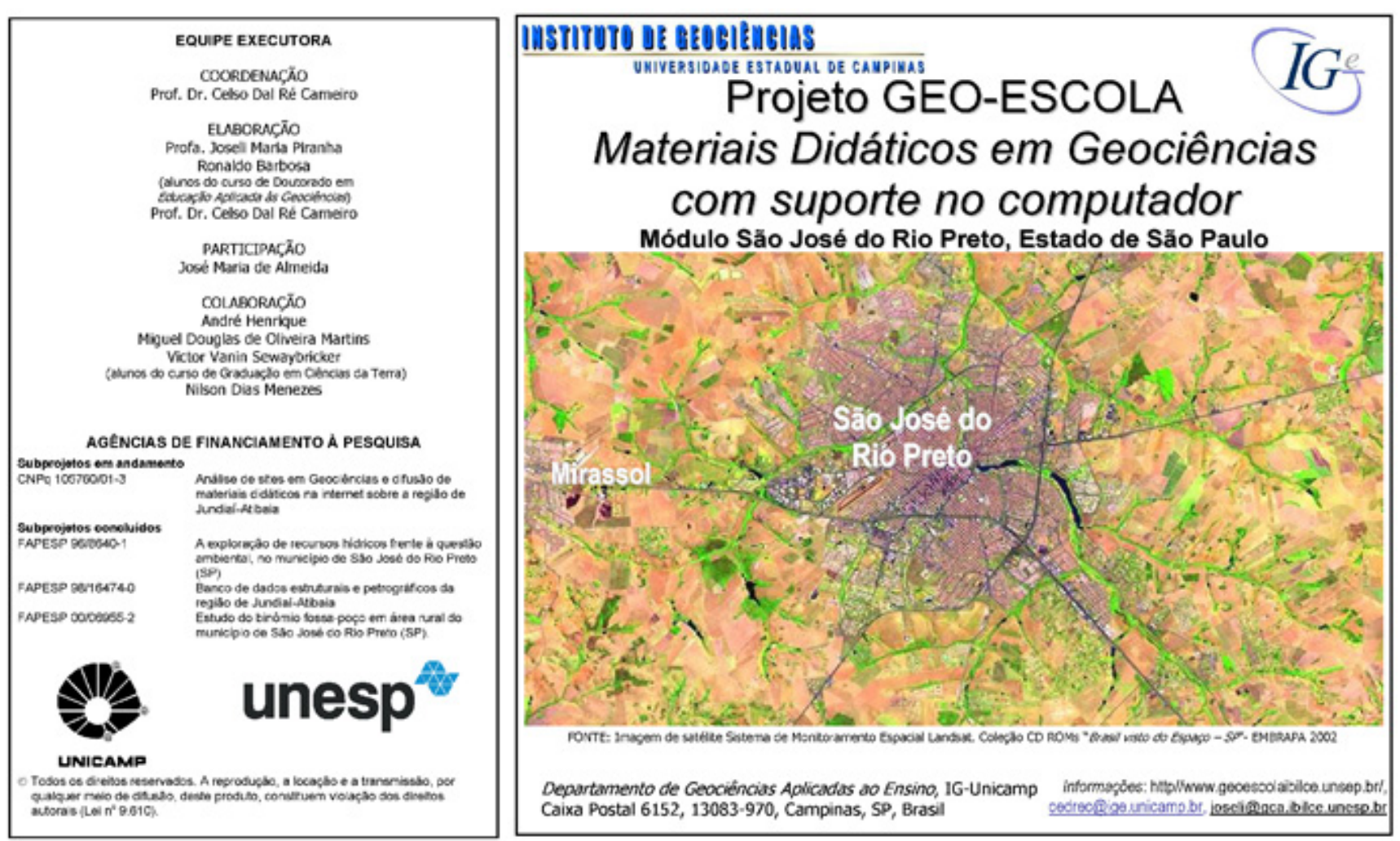

Figura 1 - Capa do CD-ROM educativo utilizado como instrumento da investigação. 
da autora. São mapas temáticos - em consonância com as metodologias dos trabalhos que lhes deram origem - que ilustram a distribuição no sítio urbano do município das ocorrências registradas como fontes potenciais de degradação de recursos hídricos. Na pasta ainda foi disponibilizado texto que relata detalhadamente e ilustra as ocorrências registradas nos mapas e descreve outros aspectos relativos ao município.

Definição e perfil da comunidade educacional Para constituir o grupo de estudo foram contatados todos os estabelecimentos de ensino, atuantes na educação básica em São José do Rio Preto. Esta iniciativa permitiu conhecer a demanda local pelo conhecimento de Geociências, quer pelas manifestações espontânea de interesse dos educadores em participar do trabalho, quer pela priorização apontada por estes, relativamente às carências e necessidades específicas identificadas para o exercício do ensino de Geo(Ciências).

O público-alvo do Projeto Geo-Escola - professores de ensino fundamental e médio, interessados em participar do trabalho - emergiu de 42 estabelecimentos de ensino, cerca de $45 \%$ daqueles que foram contatados.

Para fins de descrição do perfil pessoal e das demais avaliações pertinentes a este público, ser-lhe-á atribuído o nome de grupo de participantes.

Descrição do grupo de participantes $O$ grupo apresentou o predomínio de mulheres $(82 \%)$ e ainda o maior número de interessados $(69 \%)$ correspondia a professores de estabelecimentos de ensino público. Pouco mais da metade (53\%) dos professores lecionava Geografia, enquanto menor número (47\%) lecionava Ciências. Notou-se, contudo um número significativo de professores que respondeu lecionar, além destas, outras disciplinas, a saber: Biologia (18\%), Química $(8 \%)$, História (7\%), Matemática (4\%), Física (4\%) e Língua Portuguesa (3\%). Também se revelou um número significativo de professores das séries iniciais da educação básica (PEB 1), perfazendo 9\% daqueles que manifestaram interesse pela investigação.

A maioria $(75 \%)$ dos professores ministrava aulas para o segundo ciclo do ensino fundamental $\left(5^{\mathrm{a}}\right.$ a $8^{\mathrm{a}}$ série), $54 \%$ para o ensino médio, $25 \%$ só para o primeiro ciclo do ensino fundamental, e ainda $1,5 \%$ informaram lecionar também no ensino superior.

Os interessados são em sua maioria formados em curso superior. Predominam os formados em Geografia (27\%), seguidos por aqueles formados pelo magistério (19\%), licenciatura plena em Ciências (18\%), Pedagogia e Ciências Biológicas, ambas com $10 \%$ dos interessados; menor número $(5 \%)$ de interessados cursou a extinta História Natural. Os demais $(11 \%)$ indicaram ter concluído um dos seguintes cursos: Direito, História, Ciências Físicas, Estudos Sociais, Matemática, Psicologia e Química. Os cursos de formação em escolas públicas (Unesp, USP, universidades federais) foram minoria (34\%), se comparados àqueles de escolas particulares. A totalidade das insti- tuições distribui-se em municípios paulistas, havendo predomínio de instituições particulares do próprio município de São José do Rio Preto.

Os percentuais correspondentes à participação em cursos de pós-graduação dão destaque a cursos de especialização (68\%), sobre mestrado (5\%) e em menor número doutorado $(3,8 \%)$. Neste caso, a maioria das instituições de formação corresponde àquelas públicas, nomeadas anteriormente.

A obtenção de título acadêmico (graduação) correspondente à formação universitária deu-se para a maioria dos interessados (40\%) há cerca de 10 a 20 anos, contudo verificou-se distribuição ampla para os demais, a saber: (10\%), com menos de 5 anos; $(15 \%)$, de 5 a 10 anos; (28\%), de 20 a 30 anos: e (7\%) com mais de 30 anos de formado.

Os professores indicaram trabalhar anualmente com variado número de alunos. Predominaram os que têm por ano menos que 100 alunos, perfazendo $30 \%$ do total dos participantes. Os que lecionam para cerca de 300 alunos somam $10 \%$ dos professores; para 400 alunos, são $10 \%$; para 500 alunos, são $18 \%$; para 600 alunos: $20 \%$; para 800 alunos: $8 \%$ e para mais de 1.000 alunos/ano: $4 \%$. Depreende-se, portanto, que metade dos professores possui, em média, mais de 400 alunos por ano.

Interesses e motivações específicas A priorização dos temas de Geociências apontada pelos professores é apresentada na figura 2 .

Os temas, em geral, foram pontuados como de interesse médio a alto. Contudo, nítida preferência recaiu sobre os temas voltados aos recursos hídricos (temas 10 a 13 e 16), às questões ambientais (temas 14, 15, 17 e 19) e aos aspectos de ocupação do espaço físico local frente ao desenvolvimento (temas 20, 21 e 22).

Pode-se avaliar também, com maior detalhe, as preferências e priorizações de temas que os professores expressavam, face à carência de materiais didáticos e que, portanto, julgavam mais importantes para suas escolas. Nesse sentido, o tema mais escolhido (40 pontos) foi o 21 (Geologia da região de São José do Rio Preto), os temas 20,19 e 1 foram, nesta ordem os outros mais votados com maior grau de prioridade. Como prioridade 2, o tema 20 (Recursos naturais e o desenvolvimento sustentável) recebeu o maior número de pontos, seguido pelos temas 21 e 22. Em prioridade 3 os temas 19 (Lixo: aterros, lixões, tratamentos e reaproveitamento) e 20 foram igualmente os mais pontuados, seguidos de perto pelos pontos atribuídos ao tema 22 (Roteiros de campo para Educação Ambiental).

Buscou-se identificar ainda quais os temas que os professores interessados julgavam sentir-se mais bem preparados para ensinar, e aqueles que lhes oferecem maiores dificuldades. Assim foram pontuados os temas 11 (Ciclo da água) e o 14 (Poluição e contaminação ambientais) como os de melhor preparo. Em contrapartida, o tema 21 (Geologia de São José do Rio Preto) e o tema 6 (Tempo geológico e fósseis) foram, respectivamente, identificados, como sendo os de maior dificuldade para os educadores. 


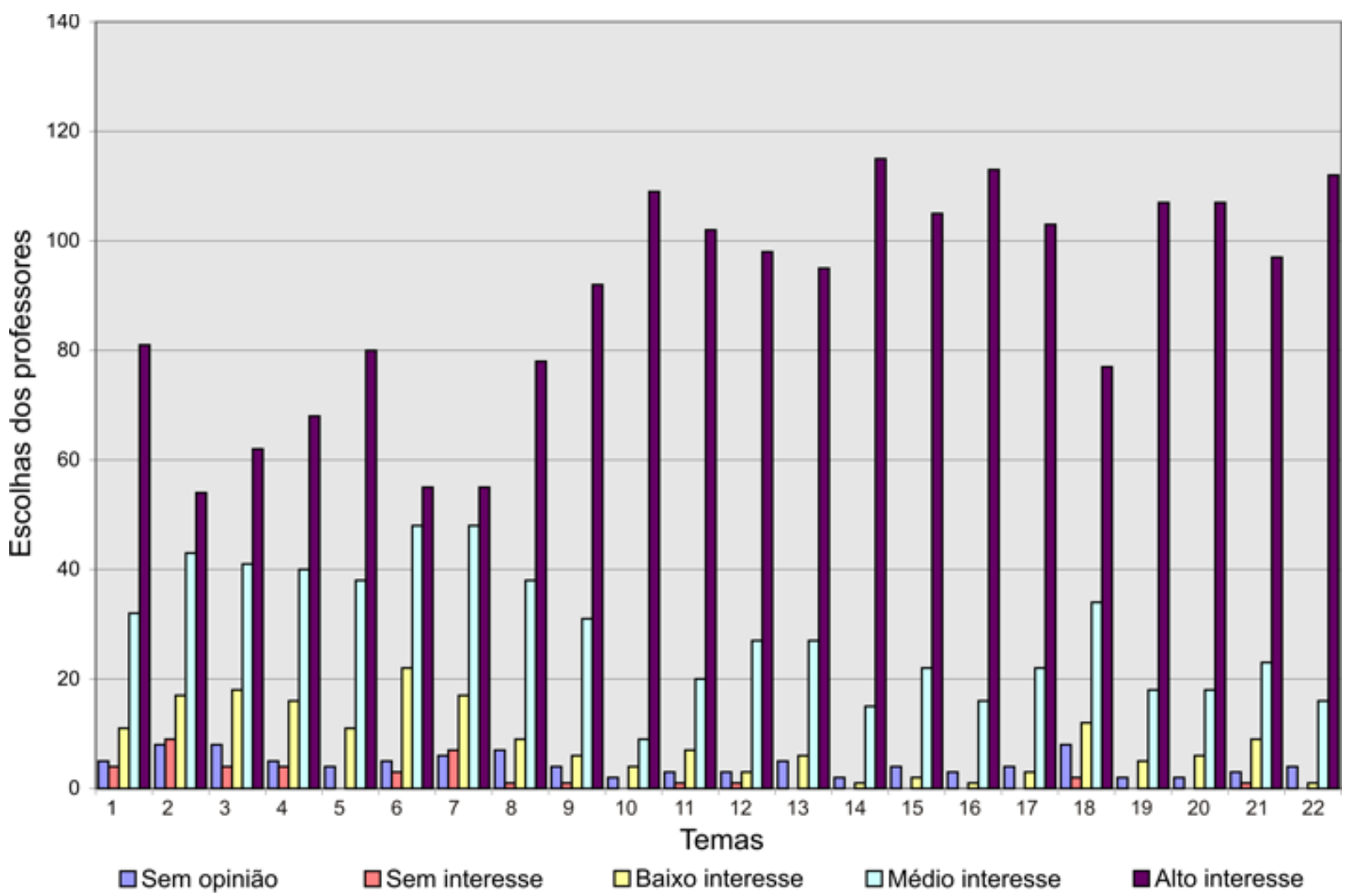

Figura 2 - Interesse prévio dos professores pelos temas de Geociências.

Condições específicas reveladas pelo grupo de participantes Pode-se constatar na definição da comunidade educacional: (a) a existência de um público interessado e disposto a participar dos trabalhos; (b) a incidência de espontânea manifestação de interesse individual, por parte desse público; (c) os interessados, educadores de ensino básico, representam parcela da sociedade detentora de grande potencial multiplicador e difusor do saber: a este público compete, em maior grau, a formação/desenvolvimento de competências/habilidades cognitivas, mediante o ensino e aprendizagem; (d) o forte interesse e motivação, específicos pelo trabalho de ensino-aprendizagem de Geociências, permitiram reconhecer as necessidades e carências que os educadores enfrentam, em sua atividade profissional, e mostram quanto estes se preocupam com o êxito do processo educacional; (e) a priorização dos temas de Geociências revelada pelos interessados apontou os temas voltados para as questões ambientais como os mais relevantes para o exercício da docência; (f) o reconhecimento, como válido, do uso dos materiais e recursos áudio-visuais para fins didáticos; $(\mathrm{g})$ o caráter incipiente do uso do computador e das tecnologias informatizadas para ensino, não obstante o fato de que grande parte das escolas já se encontra aparelhada ou empenhada na obtenção dessa infraestrutura.

A EXPERIÊNCIA EDUCACIONAL À elaboração do material didático (CD-ROM) seguiu-se um conjunto de atividades que envolveu etapas de formação, reflexão e avaliação. Como atividades de formação foram desenvolvidos e oferecidos seis cursos, na forma de módulos de 30 horas (Quadro 1).

Em todos os módulos foram realizadas atividades teóricas e práticas, sendo que nos dois primeiros

Quadro 1 -Cursos teórico-práticos oferecidos aos participantes da investigação.

\begin{tabular}{l|l}
\hline Curso & Enfoque \\
\hline $\begin{array}{l}\text { C1 - Uso do computador } \\
\text { no ensino }\end{array}$ & $\begin{array}{l}\text { Aspectos teóricos e } \\
\text { conceituais }\end{array}$ \\
\hline $\begin{array}{l}\text { C2 - Uso do Editor Geo- } \\
\text { Escola }\end{array}$ & $\begin{array}{l}\text { Reconhecimento da } \\
\text { ferramenta }\end{array}$ \\
\hline C3 - Temas de Geociências & $\begin{array}{l}\text { Aspectos teóricos e } \\
\text { conceituais }\end{array}$ \\
\hline $\begin{array}{l}\text { C4- Temas de Geociências } \\
\text { (referenciais práticos em } \\
\text { campo) }\end{array}$ & Área rural e urbana de SJRP \\
\hline $\begin{array}{l}\text { C5 - Temas de Geociências } \\
\text { (referenciais práticos em } \\
\text { campo) }\end{array}$ & $\begin{array}{l}\text { Região Noroeste do Estado } \\
\text { de SP }\end{array}$ \\
\hline $\begin{array}{l}\text { C6 - Temas de Geociências } \\
\text { (referenciais práticos em } \\
\text { campo) }\end{array}$ & $\begin{array}{l}\text { SJRP - São Paulo - litoral } \\
\text { paulista }\end{array}$ \\
\hline
\end{tabular}


módulos - Uso do Computador no Ensino e Uso do Editor Geo-Escola - as atividades práticas foram realizadas em laboratório de informática (LIM - Laboratório de Informática Multiusuário - UNESP/SJRP). Nestes módulos os professores foram convidados a "experimentar" o uso do computador e a refletir sobre o uso da tecnologia no ensino.

Nos cursos relacionados à temática das Geociências (módulos 3 a 6) optou-se pelo uso de projeções em multimídia não somente com o intuito de apresentar os materiais didáticos do CD-ROM, mas também e principalmente para motivar os professores a utilizar tais recursos. Além do CD-ROM, entregue inicialmente aos professores, no decorrer das atividades foi elaborado mais um material digital, de caráter complementar aos materiais preliminares. As apresentações do segundo CD-ROM foram elaboradas com o intuito específico de abordar os conceitos e temas tratados nos cursos 3 a 6 .

As atividades práticas desses cursos foram realizadas em três excursões didáticas para trabalhos de campo, uma de dois dias no próprio município (área rural e urbana), outra de três dias na região noroeste do Estado de São Paulo e por fim uma de quatro dias desenvolvida em percurso por unidades estratigráficas da Bacia do Paraná, embasamento cristalino e ambientes deposicionais recentes. Nestes buscou-se: (a) ordenar a apresentação dos tópicos e conhecimentos tratados partindo-se da esfera local para a regional e desta para um contexto maior: continental e/ou global; (b) organizar os conhecimentos de tal forma que se pudesse evidenciar a sucessão de eventos, fatos, fenômenos enfim; (c) apresentar e evidenciar fatos, feições, fenômenos, agentes, materiais, processos e produtos de tal forma que os professores fossem levados a reconhecer os vínculos entre estes e assim, pudessem apreender a visão sistêmica das Geociências; (d) permitir que, pelos vínculos e correlações, advindos da compreensão sistêmica, os professores pudessem realizar reflexões fundamentais para a compreensão e o dimensionamento da responsabilidade e comprometimento humano para com a realidade ambiental; (e) criar oportunidades para que os professores apresentassem suas dúvidas, incertezas e interesses, considerando que estes retratam tanto particularidades da formação original dos educadores - específicas do que concerne ao ensino de Geociências - quanto seus valores, princípios, motivações e potencialidades.

Optou-se ainda pela utilização da prática de elaboração de diários de itinerância (Barbier 2002). Além de arquivar o registro de toda a evolução dos trabalhos realizados por cada participante, o diário também desempenhou o papel de caderneta, nos trabalhos de campo. Dessa forma, os professores puderam reunir, em seus diários, rico material didático, que potencializa o preparo de novos recursos didáticos informatizados.

Outra prática também explorada para ensinoaprendizagem foi a de promoção de leituras e reflexões interpretativas correlacionadas. Estas foram dosadas segundo as necessidades da investigação e o grau de in- teresse e aceitação dos professores. Em todos os encontros didáticos buscou-se promovê-las, quer na forma de textos curtos ou mesmo de frases, escolhidas consoante os propósitos da investigação. Os próprios elementos, ferramentas e mecanismos de avaliação incorporaram parte destes recursos.

As etapas de avaliação valeram-se de recursos diversos, desde a leitura detalhada dos diários de itinerância até a análise de respostas aos questionários e avaliações de conteúdo apreendido. Por fim foram elaborados indicadores de avaliação objetiva, para efeito de análise da contribuição que a pesquisa possa ter aportado para o conjunto de professores participantes.

DISCUSSÃO Os resultados oriundos da investigação permitiram identificar, avaliar e até mesmo destacar contribuições que esses trabalhos proporcionaram para o conjunto de professores participantes e, por extensão, para as instituições e comunidades em que eles atuam. Revelaram ainda outros aspectos que conduzem a reflexões relativas ao contexto e à dinâmica pessoal e coletiva de construção do saber de Geociências, no âmbito do ensino formal e de certa forma, também no não formal.

Nesse sentido, os indicadores de avaliação objetiva adotados mostraram-se pertinentes porque facilitaram centrar o alvo da investigação - estudar/ pesquisar e avaliar o potencial, e em que medida, o conhecimento das Geociências pode contribuir para formação de uma cultura de sustentabilidade da vida no planeta. Antes de aprofundar a discussão, faz-se necessário tecer algumas considerações sobre aspectos revelados pelo público participante, antes da realização das atividades investigativas e que não devem ser equivocadamente entendidos como resultantes da experiência.

O perfil do grupo de participantes da investigação revelou público constituído por educadores da rede pública de ensino básico, em sua maioria professores já efetivados junto à rede. Embora apresentassem formação diversamente constituída, todos estavam relacionados ao ensino de Geociências na educação básica, ministrando o conteúdo destas, em abordagens esparsas no conteúdo de disciplinas de Geografia, Ciências, Física, Biologia e outras.

Da variada gama de interesses prévios revelados por esse grupo, pôde-se considerar que a maioria dos professores reconhecia a necessidade de aprofundar conhecimentos específicos das Geociências, em reconhecimento a uma formação básica insuficiente para o exercício pleno e seguro das suas atividades docentes. Esse é o primeiro aspecto do estudo a ser destacado, porque remonta à origem da formação acadêmica dos educadores e revela que o professor atribui alguma importância ao conhecimento das Geociências, por reconhecer-se carente deste. Obviamente, constitui claro sinal de que o ensino de Geociências na formação de professores deve ser revisto, valorizado e incrementado, para que estes profissionais possam exercer a do- 
cência com maior segurança e desenvoltura.

Outro aspecto relevante, também evidenciado pelo perfil do grupo, é o forte interesse e disposição dos professores para agregarem novos conhecimentos e recursos às suas práticas profissionais. Conjugam-se o interesse pelo uso de novos recursos e tecnologias para complementar o material didático, reconhecidamente insuficiente para as abordagens dos temas de Geociências, e o interesse pelo aprimoramento pessoal para exercício da atividade docente, evidenciando tratar-se de profissionais sensíveis, atentos e comprometidos com a educação.

Notou-se ainda na análise do perfil do profissional que apenas um pequeno número (17\%) de membros do grupo de participantes manifestava reconhecer relações entre os conhecimentos das Geociências e os temas relacionados à Ecologia e aomeio ambiente, sendo este um dos motivos para que tais professores se sentissem interessados em participar dos trabalhos propostos. Por outro lado, a atividade de campo já se mostrava atraente para $26 \%$ dos participantes, como instrumento de reconhecimento do meio e prática pedagógica.

Porque também deverá ser objeto de discussão, cumpre mencionar que no início do programa os participantes atribuíram valor ao material didático - o CD-ROM Geo-Escola, módulo São José do Rio Preto (Carneiro et al. 2004) -, em função de aspectos práticos e possibilidade de acesso a informações diversas, sem contudo, neste momento atribuir aos materiais um valor específico para ensino das Geociências e, menos ainda, estabelecer possíveis vínculos deste para fomento a uma cultura de sustentabilidade.

Indicador de avaliação 1 "O módulo ofereceu uma visão de conjunto a respeito de como a Terra funciona e da dinâmica de inter-relações entre recursos naturais do meio físico e os seres vivos?"

Das respostas às avaliações prévias aos cursos, pode-se notar que os participantes não evidenciaram reconhecimento dos vínculos que o Sistema Terra possui entre seus componentes. Pode-se notar que os professores traziam vaga idéia da importância dos processos geológicos para a evolução biológica e revelavam dificuldades em reconhecer causalidades. Dessa forma, as respostas evidenciaram forte antropocentrismo, destacando a importância da ação antrópica não apenas como interferente, mas como plena controladora das condições ambientais. A inexistência da compreensão escalar de tempo geológico, da natureza dos processos e da magnitude das relações que se estabelecem, em múltiplas dimensões, entre os constituintes das esferas sólidas e vivas do planeta, revelam importantes falhas conceituais e mesmo dificuldades de entendimento do significado da sustentabilidade (WCED, 1987).

As atividades realizadas nos dois primeiros módulos dos cursos, cujo enfoque voltou-se ao uso da tecnologia para o ensino, não revelaram mudanças significativas da noção que os professores traziam, dos vínculos entre os recursos físicos do planeta e a vida, que deles depende essencialmente. Contudo, já nesses módulos, intentava-se, por meio do material digital do programa - CD-ROM elaborado com conteúdo centrado no uso da informação geológica local promover reconhecimento dos aspectos relacionados às Ciências da Terra, que silenciosamente permeiam o cotidiano e o espaço de vivência dos professores. Acreditava-se que este recurso pudesse constituir uma espécie de convite à reflexão, que certamente conduziria os participantes ao interesse pelo entendimento das Geociências, e por consequência do Sistema Terra e seus significados.

Apontamentos dos professores revelaram que ao longo de todas as atividades realizadas nos demais módulos de cursos, houve crescente entendimento (ou reconhecimento) da importância das Ciências da Terra para compreensão do processo histórico de desenvolvimento e evolução da vida. O relato de um professor sugere a compreensão holística das Ciências da Terra e as destaca como "pano de fundo" para a evolução da ciência:

\begin{abstract}
"Se os conhecimentos básicos e clássicos das Ciências forem ensinados, tudo o mais pode ser a ele acrescentado, pois fará sentido e permitirá o avanço do saber. Sem esse conhecimento não se consegue evoluir a compreensão, porque as coisas perdem o sentido. É isso que temos visto atualmente: as pessoas não conseguem pensar e entender o mundo em que vivem, porque não têm conhecimento básico do que ele é."
\end{abstract}

Notou-se ainda crescente motivação dentre os participantes, no sentido de desejarem ampliar ainda mais a própria cultura profissional. Este aspecto foi revelado nas iniciativas de alguns dos participantes que, concomitantemente aos cursos, passaram a buscar meios para ingresso em estudos de pós-graduação e até mesmo de graduação.

Indicador de avaliação 2 "Os recursos utilizados como práticas pedagógicas - uso da informação geológica local, trabalhos de campo e apoio informatizado para o ensino - ofereceram aprendizagem significativa, para fins de promover mudanças de comportamento e responsabilidade individual e coletiva dos participantes e/ou de seus alunos?"

O uso da informação local foi destacado desde o início dos cursos e tornou-se crescente em diversos apontamentos dos diferentes participantes, ao longo de todas as etapas. Esse resultado ficou evidente, em especial, nos trabalhos que os alunos dos participantes elaboraram ao difundir os materiais nas escolas, na medida em que os professores passaram a incorporar as imagens e os conhecimentos da realidade local em seus próprios trabalhos.

Em muitos trabalhos elaborados, quer pelos educadores, quer pelo seu alunado, podem ser notados vínculos explícitos do aproveitamento dos recursos do GeoEscola na realização de uma aprendizagem significativa e eficaz para promover mudanças de comportamento e 
senso de responsabilidade individual e coletiva.

Os participantes reconheceram que o módulo Geo-Escola lhes proporcionou instruções sobre as ferramentas da informática, além de disponibilizar conhecimentos, material ilustrativo e referenciais teóricos da região, permitindo assim a elaboração de seus próprios materiais didáticos, auxiliando-os no incremento do uso da tecnologia no ensino e trazendo melhoras para o processo ensino-aprendizagem. Alguns relatos dos participantes ao descrever as próprias experiências com seus alunos permitem evidenciar o alcance dos materiais e práticas pedagógicas do programa, no propósito específico de promover reflexões e mudanças de atitudes individuais e coletivas. Outros relatos destacam ainda que a experiência educacional, desenvolvida com os materiais do programa, ganhou novos matizes, que tornaram agradável e gratificante o trabalho, tanto docente quanto discente.

Outro aspecto revelado pelos participantes ao tratar do uso das tecnologias e dos novos recursos didáticos no ensino, reporta ao terreno comportamental e de humanização que a prática docente propicia e que a escola por excelência pode facultar:

\footnotetext{
"A escola é também um local de convívio social e não apenas de ensino, aprender a fazer, aprender a conviver, aprender a ser e aprender a aprender só é possível com a convivência humana".
}

Outro participante destaca que a "mediação do professor, a relação de afeto, de vínculo, os elos que são estabelecidos, não são substituídos" pela tecnologia na aprendizagem. O papel humanista da prática educacional é assim destacado pelos professores como justificativa para a demanda de crescente desenvolvimento e evolução intelectual dos educadores. A necessidade de mudanças de comportamento e responsabilidade individual emerge neste contexto com forte vínculo à eficácia do processo ensino-aprendizagem.

A introdução dos conceitos geológicos em abordagens teórico-práticas, visando promover o conhecimento das Geociências e especialmente da geologia local e suas implicações na definição do contexto ambiental da região, onde vivem os participantes, pode ter exercido, junto ao grupo de participantes, o que Orion (2001: 99) adverte possível às Ciências da Terra propiciarem nos currículos escolares: “(...) o desenvolvimento da consciencialização e da compreensão ambientais" nos cidadãos.

Pôde-se notar, a partir de então, nos apontamentos dos professores, crescente reconhecimento da visão sistêmica das Ciências da Terra. Isso evidenciou-se quando os participantes passaram a trabalhar os conceitos de Geociências como meio para integrar os saberes dos demais campos científicos. Observou-se crescente reconhecimento de capacidade e motivação para desenvolvimento de trabalho interdisciplinar, nesse caso possibilitando realizar não apenas a interdisciplinaridade temática - conforme sugerem os Parâmetros Curriculares Nacionais para as abordagens relaciona- das ao ambiente - mas principalmente uma interdisciplinaridade conceitual que, como destacado nos pressupostos teóricos, é ainda mais valiosa e profícua ao aprendizado consequente e sustentável. Os participantes revelaram que as abordagens conceituais, que dão a fundamentação teórica das Geociências, permitiram que eles incorporassem a noção escalar de tempo geológico às concepções prévias que tinham. Disso resulta melhor compreensão das relações de causalidade que se estabelecem entre os processos e materiais geológicos e o desenvolvimento da vida. Os participantes passaram a revelar em suas respostas maior relativização ao reconhecimento da influência antrópica, enquanto determinante essencial da dinâmica planetária. Ao mesmo tempo, passaram a reconhecer maior importância para o desenvolvimento cultural da humanidade no enfrentamento da problemática ambiental, relegando a plano secundário o entendimento de que os instrumentos legais e regulatórios são suficientes para fazê-lo.

Ao se auto-avaliarem, evidenciaram a carência de maior entendimento das Geociências, durante a formação básica que tiveram. Destacaram assim o reconhecimento da importância que o ensino das Geociências congrega para a formação cultural do indivíduo e do cidadão. Ao mesmo tempo, expressaram o desejo de ampliarem estudos para o aprendizado destes, destacando importância para conceitos básicos de Geologia e principalmente para os recursos naturais do meio físico (minerais, rochas, água e solos) que são utilizados pelo homem e constituem "substrato" ao desenvolvimento da vida.

Os trabalhos de campo no município contribuíram para que os professores reconhecessem vínculos entre as práticas desenvolvimentistas e os impactos ambientais. Embora os participantes afirmem ser uma "meta audaciosa" considerar a educação como instrumento transformador da sociedade, eles mesmos a valorizam muitíssimo, pois a ela referem-se como essencial para a vida. Os apontamentos vincularam as atividades do Geo-Escola à promoção de mudanças de cunho pessoal e reflexivo, que suscitaram neles o desejo por ações práticas, voltadas às questões ambientais e de cidadania. Alguns chegaram a relatar mudanças sequenciais que passaram a observar em si mesmos, em suas aulas e em seus alunos, conforme destaca o apontamento abaixo transcrito, e desta forma evidenciaram a contribuição dos trabalhos para uma educação comprometida com a sustentabilidade da vida.

\footnotetext{
"Pode-se considerar que o impacto exercido pelo trabalho de campo local sobre cada indivíduo foi positivo, no sentido de despertá-lo para o entendimento da responsabilidade e do compromisso que cada ser possui, frente à vida e ao planeta."
}

Então, a partir dessa noção da importância individual, cada pessoa se reconhece capaz de melhor dimensionar e constituir suas ações, valores, escolhas e vivências frente ao coletivo, ao planetário, ao lugar comum em que a vida transcorre em incessante permuta. Os apontamentos dos professores 
foram claros no sentido de mostrar que, mediante a apropriação dos conhecimentos tratados em campo, eles se sentiram motivados e capazes de disseminar o conhecimento da realidade local, que entendem passível da intervenção humana imediata, corretiva, mitigadora e promissora à vida.

Os apontamentos dos participantes, realizados no transcorrer das atividades de campo e ainda após o encerramento destas, revelaram enorme importância das atividades de campo, enquanto prática pedagógica valiosa para promover uma aprendizagem significativa e capaz de possibilitar o desenvolvimento de mudanças de comportamento individual e coletivo. Depreende-se que os trabalhos de campo propiciaram principalmente a sensibilização dos participantes, despertando neles certa identidade com o meio que os cerca. Estas atividades thes possibilitaram expor aos sentidos os conceitos e demais aspectos que a teoria lhes havia revelado, levando-os a identificar, visualizar e compreender mais profundamente estes ensinamentos, legitimando-os. Um apontamento permite mostrar a importância dos trabalhos de campo para a legitimação do conhecimento das Geociências pelo professor:

\footnotetext{
“(...) Visualizar na prática, o que se aprende na sala de aula é muito mais significativo, além de estimular maior participação e interesse, são nesses espaços que ocorre uma identificação imediata do lugar com a informação prévia, o que favorece a aprendizagem e geralmente contribuem para modificar aspectos sociais, políticos, entre outros, favorecendo um novo olhar sobre a problemática em questão."
}

Indicador de avaliação 3 "O módulo favoreceu o trabalho interdisciplinar e transdisciplinar de temas ambientais nas escolas?"

$\mathrm{O}$ apontamento de um professor, que passou a reconhecer a visão de conjunto a respeito de como a Terra funciona, revela o valor então reconhecido para as Geociências como favorecedoras da interdisciplinaridade ou transversalidade e descreve seu alcance:

\footnotetext{
"As geociências ajudam a formar uma perspectiva planetária. O desenvolvimento da uma cultura geológica vai além do mero domínio dos avanços recentes de outras ciências. A busca de um ensino mais prático e eficaz, apoiado em uma realidade vivencial, permitirá que as pessoas contem com esse ensino para sempre."
}

Considera-se que a melhor evidência de que o módulo Geo-Escola favoreceu o trabalho interdisciplinar seja o projeto desenvolvido por dois participantes em sua Escola, após o encerramento dos cursos. Desse trabalho, destacam-se dois aspectos considerados significativos: (1) os professores valeram-se dos mesmos recursos da investigação para promover junto à sua comunidade de trabalho um conjunto de atividades que lhes permitiria integrar não somente os alunos, mas toda a comunidade escolar. Obtiveram êxito quando todos os conteúdos trabalhados voltaram-se para a abordagem integrada dos recursos hídricos enquanto "fonte geradora da vida"; (2) a escola divulgou à comunidade dos bairros adjacentes os trabalhos realizados, estabelecendo assim tanto uma extensão do acesso aos conhecimentos construídos, quanto um convite à participação colaborativa e solidária de todos, para o enfrentamento da problemática maior vivenciada pela humanidade na atualidade: comprometer-se com a sustentabilidade da vida.

Ao reconhecer e atribuir valor para o trabalho interdisciplinar o professor evidencia a noção de importância da solidariedade e do compromisso ao nível do coletivo populacional, que se entende seja decorrente do avanço da noção de responsabilidade individual.

Outro professor participante valoriza a experiência realizada e também a oportunidade de realizar um trabalho interdisciplinar, e como contraponto apresenta uma crítica tanto à multiplicação de projetos "cronometrados" que, desvinculados da realidade do aluno, não os motivam. Destaca que prefere:

\begin{abstract}
“(...) trabalhar com projetos que explorem fatos do cotidiano dos alunos e que possam ser desenvolvidos mais lenta e profundamente ao longo do ano letivo. Trabalhar a realidade local do educando amplia automaticamente sua visão global e como ele pode interferir crítica e responsavelmente sobre ela. (Foi este ponto que me levou a fazer o curso, pois seria trabalhado o local). $\mathrm{O}$ enfoque local confere um novo valor à experiência, sendo que o processo de sensibilização ocorre diariamente e não momentaneamente. (...) Trabalhar dentro de um esquema que envolva observação - questionamento - coleta de dados - análise - desdobramentos - criação de soluções é uma maneira eficiente de se escapar dos livros e apostilas que direcionam os pensamentos e ações individuais. Trabalhar assim se torna mais prazeroso, gratificante e estimulante."
\end{abstract}

Nesse apontamento, o professor ainda revela um desejo pela autonomia no trabalho educacional responsável. Depreende-se que o fato de se sentirem mais seguros e motivados lhes confere autonomia para inovar suas práticas, no sentido de renovar o convívio profissional e estender aos alunos uma maior motivação e interesse pela ação educacional e cidadã.

Indicador de avaliação 4 "O módulo permitiu reconhecer a importância do ensino de Geociências para o desenvolvimento de uma consciência planetária e por uma cultura de sustentabilidade da vida no planeta?"

O conjunto de aportes que a investigação propiciou aos professores permite considerar que ao longo dos trabalhos, o ensino de Geociências lhes revelou e permitiu que eles reconhecessem a importância dos conhecimentos e saberes das ciências (que dizem básicas) para a compreensão do mundo, dos processos, da evolução e, por consequência, do desenrolar da existência humana e da vida na Terra.

Ao reconhecer essa identidade terrena os professores participantes passaram a agregar os recursos 
do programa - conhecimentos de Geociências e ferramentas didáticas - em suas práticas pedagógicas, revelando neste percurso uma crescente motivação pessoal. Esta que, levada ao coletivo escolar, favoreceu certa inovação pedagógica contribuindo para o exercício da autonomia profissional e pessoal que, por sua vez, alimenta a motivação do "cidadão planetário" (Morin \& Kern 2002).

Nesse sentido, acredita-se que a experiência foi valiosa para que os participantes se apropriassem dos saberes das Geociências na construção dos conhecimentos profissionais que, como cidadãos, demandam.

\begin{abstract}
"Como já me reportei anteriormente, o Geo-Escola aprimorou meus conhecimentos sobre o tema geociências, com uma seriedade inquestionável e com rigor científico (...). Foi relevante para o meu desenvolvimento profissional e pessoal aguçando o meu senso crítico sobre os problemas causados pela sociedade moderna, que está calcada na economia capitalista dos meios de produção, utilizando os recursos naturais de forma desmedida, apenas com uma visão de lucro imediatista, sem pensar nas gerações futuras."
\end{abstract}

Ao mesmo tempo, a experiência evidencia a consciência crítica e disposição dos professores, frente ao compromisso pessoal e profissional de que se reconhecem investidos.

Se a consciência crítica aflora as dificuldades, reconhecendo-as inerentes à formação e postura/conduta própria, revela também a necessidade de que a vivência pessoal seja revitalizada pelo conhecimento adquirido. Reflete assim, um ensino-aprendizagem efetivo, permitindo ao aprendiz incorporar os novos conhecimentos à complexa trama de valores intrínsecos que o constitui. Destaca ainda a noção de que o saber resulta inútil, se omisso, mas ganha força e razão no cotidiano do coletivo social, onde capacita a transposição dos velhos costumes, revelando-se então promissor para o futuro desejado.

Assim, o trabalho realizado aponta a importância singular (ímpar) das Geociências para a formação do indivíduo planetário (Morin, 2003), indivíduo este capaz de reconhecer seu compromisso no coletivo da vida no planeta, e que vivencia este compromisso com sentimento de elevada motivação e satisfação pessoal. Esta vivência eleva os conhecimentos das Ciências da Terra ao estado de democratização responsável, movendo as pessoas por meio de um forte sentimento solidário e de valorização e respeito à vida, que são suporte a atitudes éticas perante a sociedade.

$\mathrm{O}$ ensino de Geociências reveste-se então de especial valor porque facilita as relações de identidade e de pertinência que são exigidos para a construção da cidadania planetária (Morin 2002a).

Nesse sentido, o conhecimento local proporciona um elo entre inovação pedagógica e o exercício da autonomia individual e coletiva. Confere ao processo de ensino-aprendizagem o diferencial para a ruptura com velhos costumes e valores, porque alimenta a razão para desconstrução do que se compreende impróprio e a promoção do se que reconhece desejável (Piranha 2006).

Esses aspectos constituem novas práticas e ações educativas em atenção à situação ambiental e são ferramentas fundamentais de uma educação inovadora. Esta última contribui para:

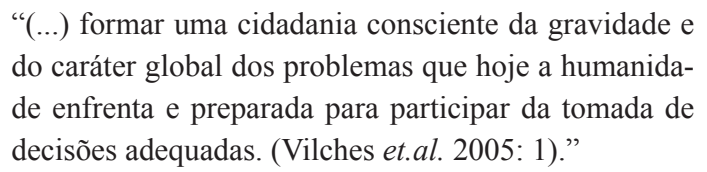

COMENTÁRIOS FINAIS Se os eixos estruturantes da investigação instigaram a tese de que ao conhecimento das Geociências cabe papel especial na educação para a sustentabilidade da vida, os resultados obtidos por meio desse estudo permitiram confirmá-la.

A pesquisa revelou que o ensino de Geociências constitui, na relação dinâmica do ensino-aprendizagem, elemento essencial para o desenvolvimento cultural do cidadão terreno, uma vez que as contribuições das Geociências ao desenvolvimento cognitivo promovem a consciência planetária. $\mathrm{O}$ uso das informações locais resultou em forte elo integrador da aprendizagem e convidou os participantes à reflexão, porque lhes mostrou a realidade do local onde vivem. Estimulou a prática reflexiva e, dessa forma, mostrou, a cada um deles, razões e meios de inovar suas atividades (práticas letivas, tratamento interdisciplinar e transdisciplinar de conceitos relacionados a recursos naturais, envolvimento pessoal com questões da coletividade).

Os participantes sentiram-se motivados a inovar criativamente e experimentar mudanças de postura, de engajamento social e de compromisso humano. Notaram que mudanças são possíveis mesmo em curto prazo.

Essa percepção evocou nos participantes o papel multiplicador da Educação, ao mesmo tempo em que lhes permitiu resgatar sentimentos valiosos: segurança, confiança, motivação, auto-estima, autonomia, liberdade, interesse pela educação continuada e permanente, reconhecimento da própria capacidade de intervir, vivência colaborativa, satisfação pessoal e amor ao ofício de educar. Levou-os a difundir esses conhecimentos e instrumentos junto aos seus pares nas Escolas, na família e na coletividade. O uso dos materiais e estratégias de ensino junto aos próprios alunos mostrouse igualmente motivador aos participantes. $\mathrm{O}$ avançar dessa experiência e a renovação das práticas didáticas sugerem uma aprendizagem significativa e motivadora (Morin, 2002).

A apropriação dos conhecimentos e as consequentes reflexões e mudanças de postura, iniciativa e vivência no grupo de participantes são marcos importantes da compreensão sistêmica que a vida exige e que as Geociências particularmente facultam. Essa parece ser rota profícua para a educação do indivíduo planetário; reconhecer sua identidade terrena constitui instrumento essencial de que a humanidade necessita, para 
as mudanças fundamentais que urge realizar em suas organizações, a fim de tornar-se sustentável do ponto de vista ecológico.

Assim, na exata medida em que a amostragem dada pelo universo de participantes possa ser considerada representativa, a pesquisa evidenciou que o cidadão planetário anseia evoluir e se mostra motivado quando efetivamente nota que isso é possível, e ao reconhecer que pela educação responsável e eficiente consegue mudar, transpor e fazer crescer com dignidade, autonomia e solidariedade.

\section{Referências}

Barbier R. 2002. A pesquisa-ação. Tradução: Lucie Didio. Brasília: Plano. 157 p. (Série pesquisa em educação, v. 3).

Brighetti J.M.P. 1992. Aspectos Físicos, Sócio-Econômicos e Sanitários de Área Indicada à Implantação de Cemitério no Município de São José do Rio Preto. In: Colóquio de Incentivo à Pesquisa, 19, São José do Rio Preto, Boletim de Resumos, p. 68.

Brighetti J.M.P., Pacheco A., Almeida D.M. 1995. O Lixo como Risco para a Saúde Ambiental no Município de São José do Rio Preto. In: SBG, Simpósio de Geologia do Sudeste, 4, Águas de São Pedro, Boletim de Resumos, p. 33.

Carneiro C.D.R. \& Barbosa R. 2003. A simple didactic tool for stimulating the use of computers in Geology Education. In: GeoSciEd IV Org. Committee/IGEO, International Conference on Geosciences Education, 4, Calgary, Conf. Proc., p. 25-26.

Carneiro C.D.R., Piranha J.M. \& Barbosa R. 2004. Projeto Geo-Escola. Materiais Didáticos em Geociências com suporte no computador. Módulo São José do Rio Preto, Estado de São Paulo. São José do Rio Preto: UNESP e UNICAMP. [1 CD-ROM: Windows XP].

Carneiro C.D.R. \& Barbosa R. 2005. Projeto Geo-Escola: Disseminação de conteúdos de geociências por meio do computador para docentes de ciências e geografia no nível fundamental em Jundiaí-Atibaia, SP. São Paulo: IGc/USP, Geologia USP, Publ. Esp., 3:71-82.

Lüdke M. \& André M.E.D.A. 2003. Pesquisa em educação: abordagens qualitativas. 6 ed. São Paulo: EPU., 101p.

Morin E. 2002. A religação dos saberes: o desafio do século XXI. Tradução: Flávia Nascimento. 3 ed. Rio de Janeiro: Bertrand Brasil, 588 p.

Morin E. 2002a. Os sete saberes necessários à educação do futuro. Tradução: Catarina Eleonora F. da Silva \& Jeanne Sawaya. 6 ed. São Paulo: Cortez, 118p.

Morin E. 2003. O método 5: a humanidade da humanidade. Tradução: Juremir Machado da Silva. 2. ed. Porto Alegre: Sulina. 312p.

Morin E. \& Kern A.B. 2002. Terra - Pátria. Tradução: Paulo Azevedo Neves da Silva. 3 ed. Porto Alegre: Sulina,
$181 \mathrm{p}$.

Orion N. 2001. A educação em Ciências da Terra. Da teoria à prática - implemantação de novas estratégias de ensino em diferentes ambientes de aprendizagem. In: Marques L., Praia J. (coords.) Geociências nos currículos dos ensinos básico e secundário. Aveiro: Univ. Aveiro, p. 93114.

Piranha J.M. 2006. O ensino de geologia como instrumento formador de uma cultura de sustentabilidade: o Projeto Geo-Escola em São José do Rio Preto, SP. Tese Doutoramento, Campinas: Inst. Geoc., Unicamp, 105p.

Piranha J.M. \& Carneiro C.D.R. 2009. O ensino de geologia como instrumento formador de uma cultura de sustentabilidade. Rev. Bras. Geoc., 39(1):2-9.

Piranha J.M., Pacheco A., Carneiro C.D.R., Rebouças A.C. \& Antonello S.L. 2004. Recursos Hídricos e Desenvolvimento. Diagnóstico básico preliminar do município de São José do Rio Preto. São José do Rio Preto: UNESP, USP e UNICAMP. [1 CD-ROM: Windows XP]. Santos C.C.M., Peresi J.T.M., Lima S. I., Silveira P.R., Brighetti J.M.P., Nascimento S.C., Zenebom O. 2001. Qualidade da água de origem subterrânea oferecida à população da Região de São José do Rio Preto (SP) no período de 1991 a 1999. São Paulo, Revista Higiene Alimentar, 15(82):47-51.

WORLD COMMISSION ON ENVIRONMENT AND DEVELOPMENT (WCED) 1987. Our Common Future. Oxford: Oxford University Press, Oxford Paperbacks 8, 400p.

Vilches A., Segarra S., Redondo L., Mira I., López Alcantud J., González M.H., Gil-Pérez D., Ferreira-Gauchía C., Calero M. 2005. Contribuición a un futuro sostenible. Una dimensión necesaria y posible en toda a acción e investigación educativa. Ensenanza de las Ciencias, Barcelona, 2005. Número Extra. URL: http://www.oei. es/decada/Vilches-482.pdf. Acesso em: 06/01/10.

Manuscrito ID 13847

Submetido em 08 de abril de 2009 Aceito em 20 de setembro de 2009 